\title{
The Effects of ELDRS at Ultra-Low Dose Rates
}

\author{
Dakai Chen, Member, IEEE, James D. Forney, Ronald L. Pease, Fellow, IEEE, Anthony M. Phan, Martin A. Carts, \\ Stephen R. Cox, Kirby Kruckmeyer, Member, IEEE, Sam Burns, Rafi Albarian, Bruce Holcombe, Bradley Little, \\ James Salzman, Geraldine Chaumont, Herve Duperray, Al Ouellet, and Kenneth LaBel, Member, IEEE
}

\begin{abstract}
We present results on the effects on ELDRS at dose rates of $10,5,1$, and $0.5 \mathrm{mrad}(\mathrm{Si}) / \mathrm{s}$ for a variety of radiation hardened and commercial devices. We observed low dose rate enhancement below $10 \mathrm{mrad}(\mathrm{Si}) / \mathrm{s}$ in several different parts. The magnitudes of the dose rate effects vary. The TL750L, a commercial voltage regulator, showed dose rate dependence in the functional failures, with initial failures occurring after $10 \mathrm{krad}(\mathrm{Si})$ for the parts irradiated at 0.5 $\operatorname{mrad}(\mathrm{Si}) / \mathrm{s}$. The $\mathrm{RH} 1021$ showed an increase in low dose rate enhancement by $2 \times$ at $5 \mathrm{mrad}(\mathrm{Si}) / \mathrm{s}$ relative to $8 \mathrm{mrad}(\mathrm{Si}) / \mathrm{s}$ and high dose rate, and parametric failure after $100 \mathrm{krad}(\mathrm{Si})$. Additionally the ELDRS-free devices, such as the LM158 and LM117, showed evidence of dose rate sensitivity in parametric degradations. Several other parts also displayed dose rate enhancement, with relatively lower degradations up to $\sim 15$ to 20 $\operatorname{krad}(\mathrm{Si})$. The magnitudes of the dose rate enhancement will likely increase in significance at higher total dose levels.
\end{abstract}

\section{INTRODUCTION}

L inear bipolar circuits are known to exhibit enhanced-lowdose-rate-sensitivity (ELDRS) in an ionizing radiation environment. The physical mechanisms for ELDRS have been discussed in several previous publications [1], [2]. ELDRS has introduced new challenges for radiation hardness assurance. The primary challenge is the significant irradiation time required to examine a part for ELDRS, which is a burden to a project's schedule and budget. There are several proposed accelerated tests, such as the elevated temperature irradiation and the switched-dose rate method [1], [3]. The

Manuscript received on July 15, 2010

This work is supported in part by the NASA Electronics Parts and Packaging program (NEPP) and the Defense Threat Reduction Agency (DTRA) under IACRO\#09-4587I.

Dakai Chen, James Forney, Martin Carts, and Anthony Phan are with MEI Technologies Inc., c/o NASA/GSFC, Greenbelt, MD, USA 20771 (phone: 301-286-8595, e-mail: dakai.chen-1@nasa.gov).

Ronald Pease is with RLP Research RLP Research, 8 Songbird Lane, Los Lunas, NM 87031 (email: 1srlpease@wildblue.net).

Kirby Kruckmeyer is with National Semiconductor, 2900 Semiconductor Dr., Santa Clara, CA 95052 (email: Kirby.Kruckmeyer@nsc.com)

Stephen Cox and Kenneth LaBel are with NASA/GSFC, Greenbelt, MD, USA 20771 (email: kenneth.a.label@nasa.gov).

Samuel Burns and Rafi Albarian are with Linear Technology Corp., Milpitas, CA, USA 95035 (email: sburns@linear.com, ralbarian@linear.com).

Bruce Holcombe, Bradley Little, and James Salzman are with Texas Instruments, Inc., 6412 Highway 75 South, Sherman, Texas, USA75090 (email: salzman@ti.com).

Geraldine Chaumont and Herve Duperray are with ST Microelectronics, Inc., 3 rue de Suisse - CS 60816, F-35208 Rennes Cedex 2, France (email: herve.duperray@st.com).

Al Ouellet is with ST Microelectronics, Inc., 10 Maguire Rd., Lexington, MA 02421 (email: ouellet@st.com). elevated temperature method is inconsistent across a variety of devices, for example the LM2941 [4]. The switched-dose rate method has several issues including the large number of samples required, and the difficulty in finding the transition dose from the threshold degradation region to the power-law region [3]. The current U.S. military test standard, MIL-STD883G TEST METHOD 1019.8, requires irradiating bipolar circuits at a minimum dose rate of $10 \mathrm{mrad}(\mathrm{Si}) / \mathrm{s}$. The low dose rate enhancement factor (LDR EF), which is the ratio of the relative degradation at low and high dose rate, is a standard figure-of-merit for ELDRS. The part is considered ELDRS sensitive if the EF for any parameter is $>1.5$, as specified in TM1019.

However the saturation dose rate for parametric degradation varies for different parts. In fact, many linear bipolar devices exhibit significant degradation for dose rates less than $10 \mathrm{mrad}(\mathrm{Si}) / \mathrm{s}$ [1], [5]. For example, the LDR EF for the LM324 increases by a factor of 6 from $5 \mathrm{mrad}(\mathrm{Si}) / \mathrm{s}(\mathrm{EF}=$ 2) to $2 \mathrm{mrad}(\mathrm{Si}) / \mathrm{s}(\mathrm{EF}=12)$. Such a large increase in degradation will exceed the $\times 1.5$ overtest factor for 10 $\operatorname{mrad}(\mathrm{Si}) / \mathrm{s}$ irradiations, as stated in TM1019.8.

Manufacturers have since produced parts that are tolerant at low dose rate environments. The ELDRS-free parts, such as the LM136 voltage reference, can exhibit less degradation at low dose rate $(10 \operatorname{mrad}(\mathrm{Si}))$ than at high dose rate [6]. But the critical question is how the ELDRS-free parts will respond at lower dose rates. There have been several recent studies on the role of hydrogen to low dose rate sensitivity [3], [5], [6]. Hydrogen contamination from certain packaging can enhance the effects of ELDRS [8]. These studies lead to the suggestion that the transition point for exhibiting ELDRS is moved to lower dose rates. Therefore while the ELDRSfree parts are guaranteed to function within specification at $10 \mathrm{mrad}(\mathrm{Si})$, the degradation may increase significantly at lower dose rates.

The perpetual introduction of new devices, with various innovative processes and circuit designs, necessitates the understanding of the different degradation behaviors at ultralow dose rates. Here we examine the effects of ELDRS for a large sample of commercial and radiation hardened devices from different manufacturers, at dose rates of $10,5,1$, and 0.5 $\operatorname{mrad}(\mathrm{Si}) / \mathrm{s}$.

\section{EXPERIMENTAL DETAILS}

We examine more than twenty different parts from Linear Technology, Texas Instruments, National Semiconductor, and ST Microelectronics. The various part types include voltage reference, voltage regulator, operational amplifiers, and voltage comparators. They include radiation hardened (lot tested at high dose rate), ELDRS-free (lot tested at $10 \mathrm{mrad}(\mathrm{Si}) / \mathrm{s})$, and commercial devices. The parts are 
TABLE I.

PARTS INFORMATION AND RESULTS SUMMARY.

\begin{tabular}{|c|c|c|c|c|}
\hline $\begin{array}{l}\text { Part Number } \\
\text { (package type) }\end{array}$ & Lot-Date-Code & Function & Irradiation Bias & Summary of Results \\
\hline \multicolumn{5}{|l|}{ Texas Instruments } \\
\hline $\begin{array}{l}\text { LT1009IDR } \\
(8-S O I C)\end{array}$ & 0606 & $2.5 \mathrm{~V}$ internal reference & All pins grounded & $\begin{array}{l}\text { Parameters within specification after } 100,30 \text {, and } 15 \\
\operatorname{krad}(\mathrm{Si}) \text { for the } 5,1 \text {, and } 0.5 \operatorname{mrad}(\mathrm{Si}) \text { parts. }\end{array}$ \\
\hline $\begin{array}{l}\text { LM317KTTR } \\
(3-\mathrm{DDPAK})\end{array}$ & 0608 & $\begin{array}{l}\text { Positive volt reg } 3- \\
\text { terminal }\end{array}$ & All pins grounded & $\begin{array}{l}\text { Parameters within specification after } 80,20 \text {, and } 15 \\
\text { krad(Si) for the } 5,1 \text {, and } 0.5 \operatorname{mrad}(\mathrm{Si}) \text { parts. } \\
\text { LDR enhancement: } 5-0.5 \mathrm{mrad}(\mathrm{Si}) / \mathrm{s}\end{array}$ \\
\hline $\begin{array}{l}\text { TL750L05CDR } \\
\text { (8-pin plastic SOIC) }\end{array}$ & 0605 & $\begin{array}{l}\text { LDO positive voltage } \\
\text { reg } 5 \mathrm{~V}\end{array}$ & All pins grounded & $\begin{array}{l}\text { LDR enhancement for functional failures. } \\
5 \mathrm{mrad}(\mathrm{Si}) / \mathrm{s}: 35<\mathrm{V}_{\text {out }}<40 \mathrm{krad}(\mathrm{Si}) \\
1 \mathrm{mrad}(\mathrm{Si}) / \mathrm{s}: 10<\mathrm{V}_{\text {out }}<15 \mathrm{krad}(\mathrm{Si}) \\
0.5 \mathrm{mrad}(\mathrm{Si}) / \mathrm{s}: 7.5<\mathrm{V}_{\text {out }}<10 \mathrm{krad}(\mathrm{Si})\end{array}$ \\
\hline $\begin{array}{l}\text { TL750M05CKTRR } \\
(\mathrm{TO} 263-3)\end{array}$ & 0707 & LDO voltage regulator & All pins grounded & $\begin{array}{l}\text { - } \mathrm{V}_{\text {out }} \text { failure levels }\left(\mathrm{I}_{\mathrm{O}}=10 \mathrm{~mA}\right) \\
5 \mathrm{mrad}(\mathrm{Si}) / \mathrm{s}: 70<\mathrm{V}_{\text {out }}<80 \mathrm{krad}(\mathrm{Si}) \\
1 \mathrm{mrad}(\mathrm{Si}) / \mathrm{s}:>20 \mathrm{krad}(\mathrm{Si}) \\
0.5 \mathrm{mrad}(\mathrm{Si}) / \mathrm{s}:>15 \mathrm{krad}(\mathrm{Si})\end{array}$ \\
\hline \multicolumn{5}{|l|}{ National Semiconductor } \\
\hline $\begin{array}{l}\text { LM117HRQMLV } \\
\text { (TO-39 metal can) }\end{array}$ & 7D5867L019 & Voltage comparator & All pins grounded & $\begin{array}{l}\text { - } \quad \text { LDR enhancement observed for } \mathrm{V}_{\text {ref }} \text { degradation. } \\
\text { - } \quad \text { Parameters within specification after } 90,20 \text {, and } 15 \\
\operatorname{krad}(\mathrm{Si}) \text { for the } 5,1 \text {, and } 0.5 \operatorname{mrad}(\mathrm{Si}) / \mathrm{s} \text { parts. }\end{array}$ \\
\hline $\begin{array}{l}\text { LM158AJRLQMLV } \\
\text { (8-lead CERDIP) }\end{array}$ & 7W4453G019 & Op-Amp & All pins grounded & $\begin{array}{l}\text { - LDR enhancement: } 5-0.5 \operatorname{mrad}(\mathrm{Si}) / \mathrm{s} \text {. } \\
5 \mathrm{mrad}(\mathrm{Si}) / \mathrm{s}(1 \mathrm{part}): 60<\mathrm{I}_{\mathrm{b}}<70 \mathrm{krad}(\mathrm{Si}) \text {. }\end{array}$ \\
\hline $\begin{array}{l}\text { LM136 } \\
(3-\text { lead TO-46) }\end{array}$ & $200746 \mathrm{~K} 019$ & Voltage Reference 2.5 & All pins grounded & $\begin{array}{l}\text { Parameters within specification after } 100,20 \text {, and } 10 \\
\operatorname{krad}(\mathrm{Si}) \text { for the } 5,1 \text {, and } 0.5 \mathrm{mrad}(\mathrm{Si}) \text { devices. }\end{array}$ \\
\hline $\begin{array}{l}\text { LM124AJRQMLV } \\
\text { (14-lead CERDIP) } \\
\end{array}$ & 9R5469G019 & Operational amplifier & Biased and grounded & In progress \\
\hline $\begin{array}{l}\text { LM139AWRQMLV } \\
\text { (14-lead CERDIP) }\end{array}$ & JM046X13 & Voltage comparator & Biased and grounded & In progress \\
\hline \multicolumn{5}{|l|}{ Linear Technology } \\
\hline $\begin{array}{l}\text { RH1013MH } \\
\text { (TO-5 metal can) }\end{array}$ & 0329A & \multirow[t]{2}{*}{ Dual precision op-amp } & \multirow[t]{2}{*}{ Biased and grounded } & \multirow{2}{*}{$\begin{array}{l}\text { Parameters within specification after } 100,20 \text {, and } 10 \\
\operatorname{krad}(\mathrm{Si}) \text { for } 5,1 \text {, and } 0.5 \operatorname{mrad}(\mathrm{Si}) \text {. }\end{array}$} \\
\hline $\begin{array}{l}\text { RH1013MJ8 } \\
\text { (Ceramic DIP) }\end{array}$ & $0305 \mathrm{~A}$ & & & \\
\hline $\begin{array}{l}\text { RH1021CMH-5 } \\
\text { (TO-5 can) }\end{array}$ & $9783 \mathrm{~A}$ & \multirow{2}{*}{ Precision 5V Reference } & \multirow{2}{*}{ All pins grounded } & \multirow{2}{*}{$\begin{array}{l}\text { LDR enhancement: } 5 \operatorname{mrad}(\mathrm{Si}) / \mathrm{s} \text {. } \\
5 \operatorname{mrad}(\mathrm{Si})(\mathrm{TO}-5): 90<\mathrm{V}_{\mathrm{z}}<100 \mathrm{krad}(\mathrm{Si}) \text {. }\end{array}$} \\
\hline RH1021CMW-5 (Flatpack) & $0123 \mathrm{~A}$ & & & \\
\hline $\begin{array}{l}\text { RH1009MW } \\
\text { (Flatpack) }\end{array}$ & $0649 \mathrm{~A}$ & \multirow[t]{2}{*}{ 2.5V Reference } & \multirow[t]{2}{*}{ All pins grounded } & \multirow{2}{*}{$\begin{array}{l}\text { ELDRS observed. } \\
5 \mathrm{mrad}(\mathrm{Si}) / \mathrm{s} \text { TO-46 cans: } 80<\mathrm{V}_{\mathrm{z}}<90 \mathrm{krad}(\mathrm{Si}) \\
5 \mathrm{mrad}(\mathrm{Si}) / \mathrm{s} \text { Flatpacks: } 100<\mathrm{V}_{\mathrm{z}}<120 \mathrm{krad}(\mathrm{Si}) \text {. }\end{array}$} \\
\hline RH1009MH (TO-46 can) & $0829 \mathrm{H}$ & & & \\
\hline $\begin{array}{l}\text { RH1078MW } \\
\text { (Glass sealed Flatpack) }\end{array}$ & $0741 \mathrm{~A}$ & \multirow{2}{*}{$\begin{array}{l}\text { Single supply, precision } \\
\text { op-amp }\end{array}$} & \multirow{2}{*}{ Biased and grounded } & \multirow[t]{2}{*}{ In progress } \\
\hline RH1078MH (TO5 metal can) & $0325 \mathrm{~A}$ & & & \\
\hline \multicolumn{5}{|l|}{ ST Microelectronics } \\
\hline $\begin{array}{l}\text { RHFL4913ESY332 } \\
\text { (TO-257) }\end{array}$ & $30828 \mathrm{~A}$ & \multirow{2}{*}{ Voltage regulator } & \multirow{2}{*}{ All pins grounded } & \multirow{2}{*}{$\begin{array}{l}\text { - Negligible degradations levels. Parameters within } \\
\text { specification after } 10 \text { and } 13 \mathrm{krad}(\mathrm{Si}) \text { for the } 10 \text { and } 1 \\
\operatorname{mrad}(\mathrm{Si}) \text { devices. }\end{array}$} \\
\hline RHFL4913KP332 (Flat-16) & 30814B & & & \\
\hline RH310 (Ceramic Flat-8) & $30849 \mathrm{~A}$ & Operational amplifier & Biased and grounded & In progress \\
\hline RHF43B (Ceramic Flat-8) & $30820 \mathrm{~A}$ & $\begin{array}{l}\text { Precision single } \\
\text { operational amplifier }\end{array}$ & Biased and grounded & In progress \\
\hline
\end{tabular}

available in a variety of package types: ceramic, flatpack, metal can, and dual-inline-package (DIP). In some cases the same part is available in both flatpack/DIP and metal can packages.

The irradiations are performed with a ${ }^{60} \mathrm{Co}$ gamma ray source at room temperature. The dose rates are 10, 5, 1, and
$0.5 \mathrm{mrad}(\mathrm{Si}) / \mathrm{s}$. Four to five samples of each part are irradiated for each dose rate. At least two samples of each part are used as controls. Most of the parts, including voltage regulators and references, are irradiated with all pins grounded. The operational amplifiers and voltage 


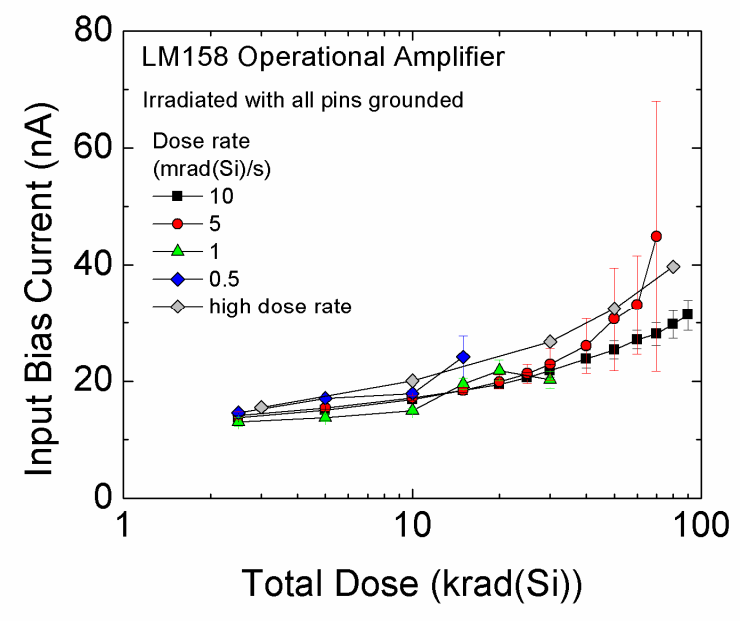

Fig. 1. Average input bias current ( 3 parts with 2 devices each) vs. TID for the LM158 operational amplifier from National Semiconductor irradiated with all pins grounded.

comparators are irradiated with both biased and unbiased (all pins grounded) conditions.

We characterized the electrical parameters onsite, with the exception of the devices from National Semiconductor, which were also shipped back to the manufacturer's testing facility at select doses. The test and bias circuits, where applicable, were fabricated in-house. We used the Agilent 6624 power supply, the HP34401 digital multimeter, and the Keithley 2425 source meter to characterize the RHF4913 and LM117 voltage regulators. We also used the HP34401 and Agilent 33250A waveform generator to characterize the CMRR and open loop gain for the operational amplifiers. In addition we used the Agilent 4156 and Keithley 4200 parameter analyzer to characterize all other parts. We used DC characterization to measure any DC parameter, whereas for some parts the parametric specifications were obtained using the manufacture's specific pulse techniques.

\section{RESULTS}

Table I. is a list of all devices under investigation. The table includes the part number, package type, lot-date-code, part function, bias configuration, and a short summary of results. Here we show highlight results from several select parts.

\section{A. $\quad$ LM158A}

The LM158AJRQMLV is an ELDRS-free low power dual operational amplifier manufactured by National Semiconductor, qualified up to $100 \mathrm{krad}(\mathrm{Si})$ at $10 \mathrm{mrad}(\mathrm{Si}) / \mathrm{s}$. Figure 1 shows the average input bias current $\left(I_{b}\right)$ vs. total dose at various dose rates. The input bias current is the average of the positive and negative input currents on one device for all parts. The error bars indicate part-to-part variation. There is minimal device-to-device variation within a package. We note that the increasing error bars for the 5 $\operatorname{mrad}(\mathrm{Si}) / \mathrm{s}$ data is due to one part showing significant degradation relative to the other two parts. The $I_{b}$ of the rogue

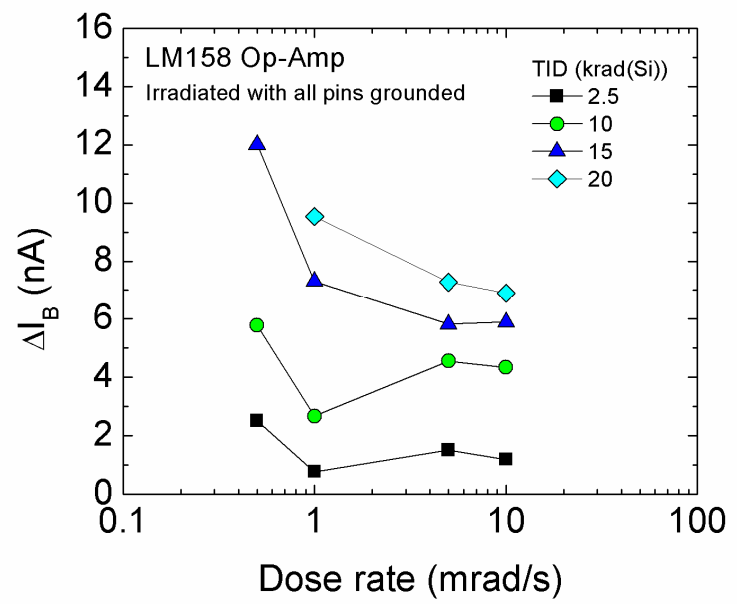

Fig. 2. Change in the input bias current vs. dose-rates at various TID levels from 2.5 to $20 \mathrm{krad}(\mathrm{Si})$ for the LM158 operational amplifier from National Semiconductor.

device increases to beyond specification ( $>50 \mathrm{nA}$ ) after 70 $\operatorname{krad}(\mathrm{Si})$.

Figure 2 shows the change in $\mathrm{I}_{\mathrm{b}}$ with dose rate at different TID levels. We observed dose rate enhancement in the $\mathrm{I}_{\mathrm{b}}$ degradation after $15 \mathrm{krad}(\mathrm{Si})$, where the degradation increases with decreasing dose rate. In general, the LDR EF for $\mathrm{I}_{\mathrm{b}}$ is less than 1, but increases with TID. The average EF for the $5 \mathrm{mrad}(\mathrm{Si}) / \mathrm{s}$ devices increases to 1.2 after $70 \mathrm{krad}(\mathrm{Si})$, owing to the enhanced degradation of one part. We will realize the significance of the dose rate enhancement at higher TID levels.

\section{B. RH1021}

The RH1021 is a voltage reference from Linear Technology previously qualified at high dose rate. We evaluate two package types: RH1021CMH (TO-5 metal cans) and RH1021CMW (10-lead ceramic flatpacks). Figure 3 shows the reference voltage $\left(\mathrm{V}_{\text {ref }}\right)$ with increasing TID at 5 and $8 \mathrm{mrad}(\mathrm{Si}) / \mathrm{s}$, and at high dose rate for the TO-5 packages. The $8 \mathrm{mrad}(\mathrm{Si}) / \mathrm{s}$ and high dose rate data show similar levels of degradation. However the $5 \mathrm{mrad}(\mathrm{Si}) / \mathrm{s}$ response showed significantly higher degradation. The LDR $\mathrm{EF}$ increases by a factor of $2 \mathrm{after} 30 \mathrm{krad}(\mathrm{Si})$. Therefore the part is ELDRS sensitive at $\leq 5 \mathrm{mrad}(\mathrm{Si}) / \mathrm{s}$. The reference voltage failed specification after $100 \mathrm{krad}(\mathrm{Si})$.

We also found that the TO-5 packages degraded more significantly than the flatpacks at dose rates of 5,1 , and 0.5 $\operatorname{mrad}(\mathrm{Si}) / \mathrm{s}$. Figure 4 compares the two package types at 5 $\operatorname{mrad}(\mathrm{Si}) / \mathrm{s}$. The results indicate that the flatpack devices here do not exhibit hydrogen contamination effects that can enhance ELDRS [8].

\section{TL750L}

The TL750L05CDR is a commercial low-dropout voltage regulator manufactured by Texas Instruments. We observed distinct dose rate dependence for the functional failures. The initial failures occur after 40, 20, and 10 


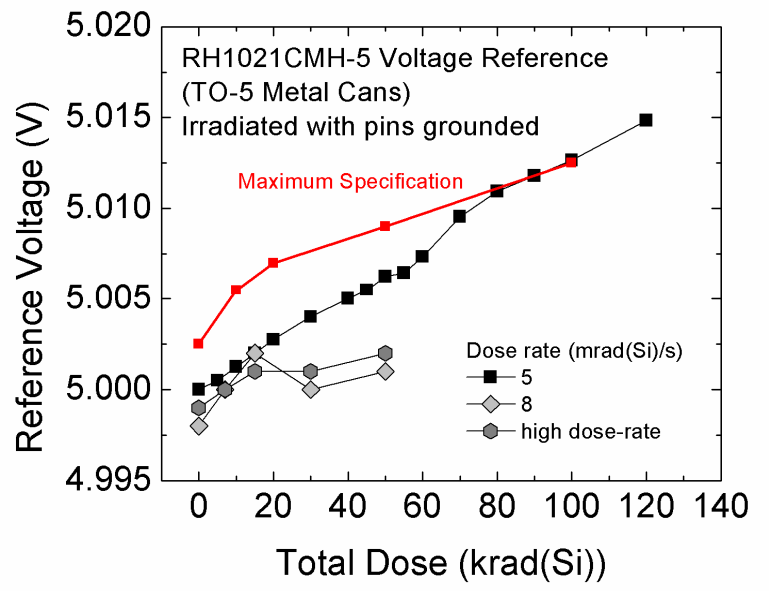

Fig. 3. Reference voltage vs. TID at different dose rates for the RH1021CMH-5 voltage reference from Linear Technology, irradiated with all pins grounded.

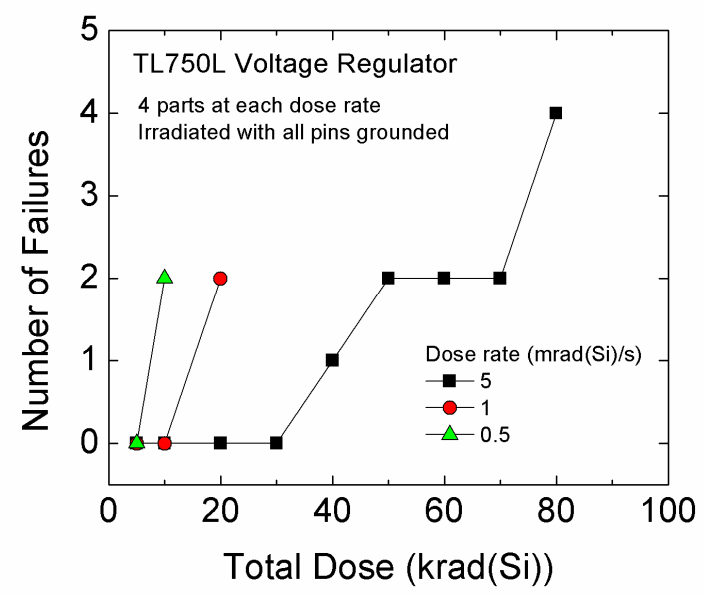

Fig. 5. Number of part failures vs. TID at different dose rates for the TL750L voltage regulator from Texas Instruments, irradiated with all pins grounded.

$\operatorname{krad}(\mathrm{Si})$ for the 5,1 , and $0.5 \mathrm{mrad}(\mathrm{Si}) / \mathrm{s}$ parts, respectively. Figure 5 shows the number of part failures (from 4 parts at each dose rate) vs. total dose. The functional failures are characterized by the failure of the output voltage $\left(\mathrm{V}_{\text {out }}\right)$ to regulate with $100 \mathrm{~mA}$ load, while remaining functional with $10 \mathrm{~mA}$ load. In most cases the part fails to regulate with 10 $\mathrm{mA}$ load at the next dose step.

The failures were abrupt, without gradual degradation to the output voltage or any other measured parameter. The degradation behavior is similar to the 29372 low-dropout regulator from a previous study [9]. The output voltage failed to regulate the preset load, as the maximum output drive current degrades with total dose [9]. Consequently the output failed to regulate for the $100 \mathrm{~mA}$ load prior to failure with the $10 \mathrm{~mA}$ load.

It is also possible that the radiation-induced leakage current becomes significant, so that the internal current limiting protection circuitry shuts down the device. This is consistent with the fact that the failed devices do not draw any current. The $10 \mathrm{mrad}(\mathrm{Si}) / \mathrm{s}$ irradiations are currently in process.

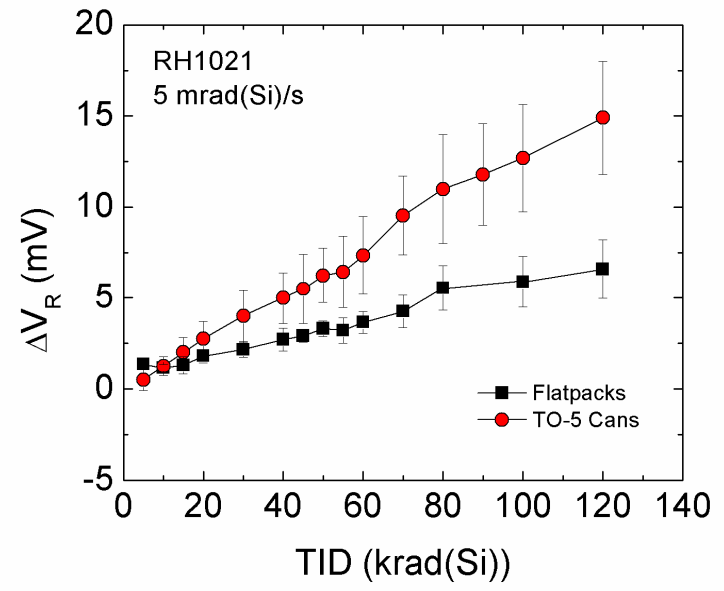

Fig. 4. The change in reference voltage vs. TID for the RH1021 voltage reference in TO-5 cans and Flatpacks, irradiated at $5 \mathrm{mrad}(\mathrm{Si}) / \mathrm{s}$ with all pins grounded.

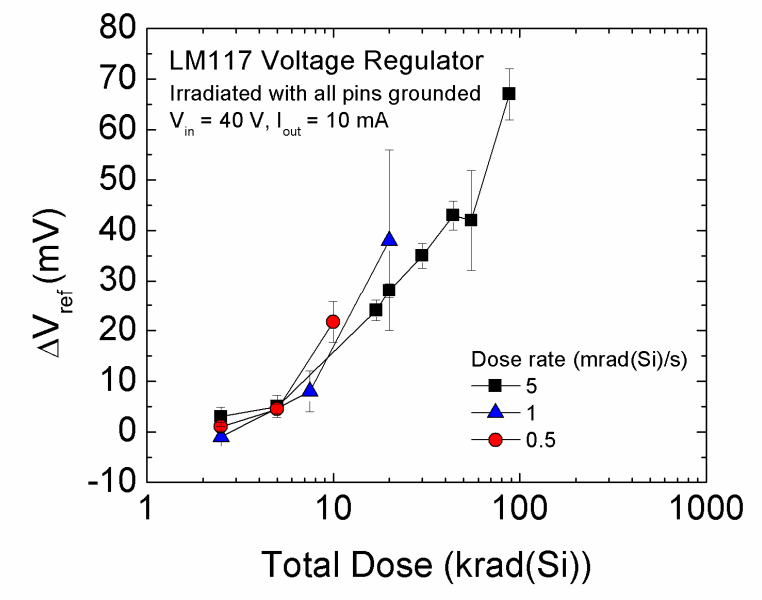

Fig. 6. Change in reference voltage vs. TID for the LM117 adjustable voltage regulator irradiated at 5,1 , and $0.5 \mathrm{mrad}(\mathrm{Si}) / \mathrm{s}$

\section{D. $L M 117 H$}

The LM117HRQMLV is an ELDRS-free adjustable positive voltage regulator manufactured by National Semiconductor, qualified up to $100 \mathrm{krad}(\mathrm{Si})$ at $10 \mathrm{mrad}(\mathrm{Si}) / \mathrm{s}$. Figure 6 shows the change in the reference voltage $\left(V_{\text {in }}=40\right.$ $\mathrm{V}$ and $\mathrm{I}_{\text {out }}=10 \mathrm{~mA}$ ) with TID at different dose rates,. Figure 7 shows the dose at which the reference voltage degrades beyond the pre-irradiation specification $\left(\mathrm{V}_{\text {ref }}=1.3 \mathrm{~V}\right)$. We observed dose rate dependence for the dose at which $\mathrm{V}_{\text {ref }}$ exceeds the pre-irradiation specification: 20,15 and 10 $\operatorname{krad}(\mathrm{Si})$ for the 5,1 , and $0.5 \mathrm{mrad}(\mathrm{Si}) / \mathrm{s}$ parts. The postirradiation specification limit for the reference voltage is 1.35 V. The dose rate enhancement will likely become more evident at higher TID levels.

\section{E. $\quad$ LM317}

The LM317KTTR is a commercial adjustable voltage regulator manufactured by Texas Instruments. The parts are 


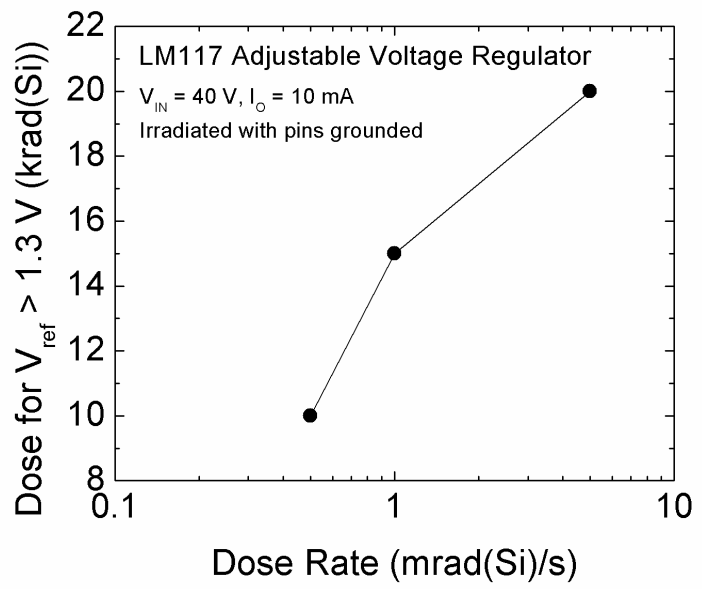

Fig. 7. Dose that $\mathrm{V}_{\text {ref }}$ exceeds pre-irradiation limit $\left(\mathrm{V}_{\text {ref }}=1.3 \mathrm{~V}\right)$ vs. dose rate for the LM117 adjustable voltage regulator..

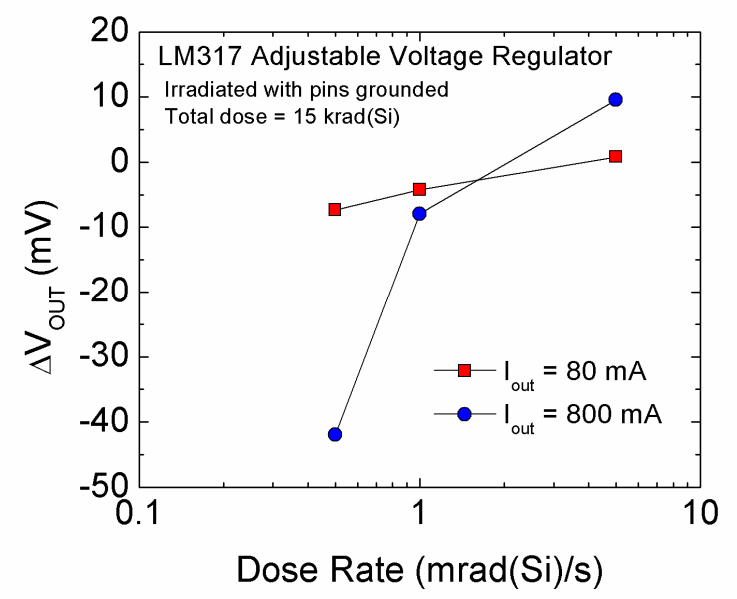

Fig. 9. Change in the output voltage vs. dose rate at $15 \mathrm{krad}(\mathrm{Si})$ for the LM317 adjustable voltage regulator operating with 80 and $800 \mathrm{~mA}$ output load.

grounded during irradiation. The device parameters, including the output voltage, line and load regulations, are within specification at this stage of the irradiation. Figure 8 shows the change in $\mathrm{V}_{\text {out }}$ with $\mathrm{V}_{\text {in }}=40 \mathrm{~V}$ and $\mathrm{I}_{\text {out }}=80 \mathrm{~mA}$. The output voltage decreases with increasing TID. Figure 9 shows the change in $\mathrm{V}_{\text {out }}$ as a function of dose rate at 15 $\operatorname{krad}(\mathrm{Si})$. We observed dose rate enhancement in the $\mathrm{V}_{\text {out }}$ degradation. The dose rate enhancement is significantly higher with the larger output load $\left(\mathrm{I}_{\text {out }}=800 \mathrm{~mA}\right)$.

\section{F. RH1009}

Figure 10 shows the reverse breakdown voltage vs. total dose for the RH1009 voltage reference manufactured by Linear Technology. Two types of packages are included: RH1009MH (TO-46 metal can) and RH1009MW (ceramic flatpack). Figure 10 also contains data from high dose rate results on parts from the same date code. We observed enhanced degradation for the $5 \mathrm{mrad}(\mathrm{Si}) / \mathrm{s}$ data relative to the high dose rate data. The LDR EF $=4.2$ and 3.6 for the TO-46 cans and flatpacks, respectively, after $50 \mathrm{krad}(\mathrm{Si})$. The EF

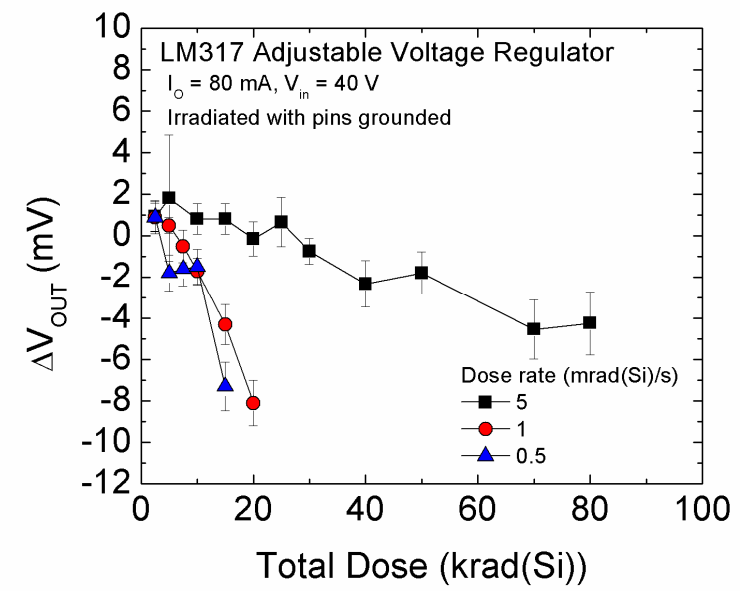

Fig. 8. Average output voltage vs. TID for the LM317 adjustable voltage regulator irradiated at 5,1 , and $0.5 \mathrm{mrad}(\mathrm{Si}) / \mathrm{s}$

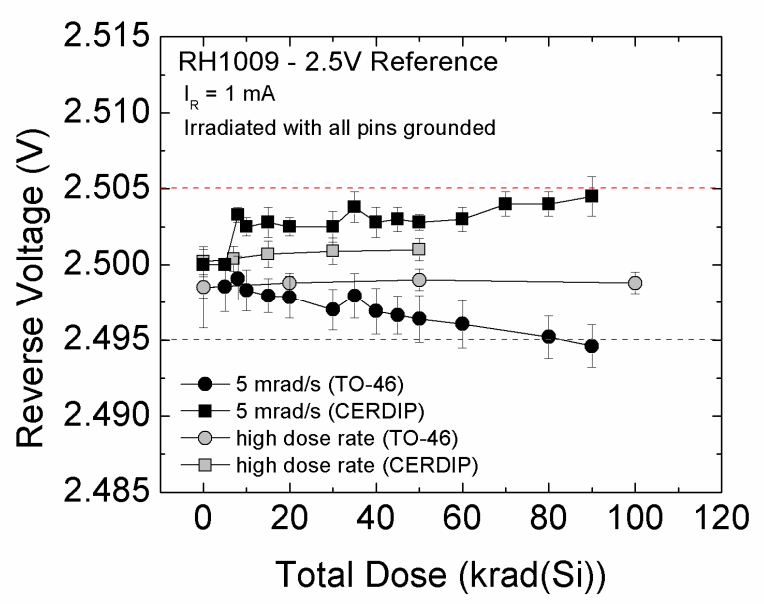

Fig. 10. Average reference voltage vs. TID for the LM117 adjustable voltage regulator irradiated at 5,1 , and $0.5 \mathrm{mrad}(\mathrm{Si}) / \mathrm{s}$.

increases to $\sim 13$ for the TO-46 devices after $90 \mathrm{krad}(\mathrm{Si})$. The average reverse breakdown voltage exceeds specification $(2.495 \mathrm{~V})$ after $90 \mathrm{krad}(\mathrm{Si})$ for the TO-46 packages. Therefore the results indicate that these devices are susceptible to ELDRS at $5 \mathrm{mrad}(\mathrm{Si}) / \mathrm{s}$.

Additionally, the TO-46 and flatpacks exhibit opposing degradation trends. The TO-46 devices showed decreasing (negative-going) $\mathrm{V}_{\text {out }}$, while the flatpack devices show increasing (positive-going) $\mathrm{V}_{\text {out }}$ with TID. The device packaging may have affected the different degradation behaviors. However we also observed increasing $\mathrm{V}_{\text {out }}$ for the 1 and $0.5 \mathrm{mrad}(\mathrm{Si}) / \mathrm{s}$ TO-46 parts. Therefore the different behaviors of the package types at $5 \mathrm{mrad}(\mathrm{Si}) / \mathrm{s}$ are more likely due to part-to-part variation.

\section{CONCLUSION}

We have presented results of the effects of ELDRS for a variety of radiation hardened and commercial devices, at dose rates varying from 10 to $0.5 \mathrm{mrad}(\mathrm{Si}) / \mathrm{s}$. We observed low dose rate enhancement in several parts, where the degradation 
increases with decreasing dose rate to as low as 0.5 $\operatorname{mrad}(\mathrm{Si}) / \mathrm{s}$. The degradation enhancement is severe for some parts. For example the TL750L exhibited dose rate enhancement for the functional failures. The initial failures occur after $10 \mathrm{krad}(\mathrm{Si})$ at $0.5 \mathrm{mrad}(\mathrm{Si}) / \mathrm{s}$. While the RH1021 displayed similar degradation levels at $\sim 8 \mathrm{mrad}(\mathrm{Si}) / \mathrm{s}$ as at high dose rate, the low dose rate EF increased by a factor of 2 at $5 \mathrm{mrad}(\mathrm{Si}) / \mathrm{s}$, after $30 \mathrm{krad}(\mathrm{Si})$. Parametric failure occurs after $100 \mathrm{krad}(\mathrm{Si})$.

The cases presented here, in addition to previous examples in [1], illustrate the significance and pervasiveness of low dose rate enhancement at dose rates lower than 10 $\operatorname{mrad}(\mathrm{Si})$. The ELDRS-free devices, as shown for the LM158 and LM117, are also susceptible to enhanced degradation at the lower dose rates. The low dose rate EF for the devices that exhibit dose rate enhancement will likely continue to increase with increasing total dose, until we establish the transition dose for exhibiting ELDRS $(\mathrm{EF}=1.5)$, followed by the damage saturation point. These results present further challenges for radiation hardness assurance of bipolar linear circuits.

\section{ACKNOWLEDGEMENT}

This work was supported in part by the NASA Electronic Parts and Packaging Program (NEPP) and the Defense Threat Reduction Agency (DTRA) under IACRO\# 10-4977I.

The authors would like to thank Tom Ward and Yevgeniy Geraschenko for organizing the radiation schedule.

\section{REFERENCES}

[1] R. L. Pease, R. D. Schrimpf, and D. M. Fleetwood, "ELDRS in bipolar linear circuits: a review," IEEE Trans. Nuc. Sci., vol. 56, Aug. 2009, pp. $1894-1908$.

[2] D. M. Fleetwood, S. L. Kosier, R. N. Nowlin, R. D. Schrimpf, R. A. Reber, Jr., M. DeLaus, P. S. Winokur, A. Wei, W. E. Combs, and R. L. Pease, "Physical mechanisms contributing to enhanced bipolar gain degradation at low dose rates," IEEE Trans. Nuc. Sci., vol. 41, Dec. 1994, pp. $1871-1885$.

[3] J. Boch, Y. G. Velo, F. Saigne, N. J.-H. Roche, R. D. Schrimpf, J-R. Vaille, L. Dusseau, C. Chatry, E. Lorfevre, R. Ecoffet, and A. D. Touboul, "The use of a dose-rate switching technique to characterize bipolar devices," IEEE Trans. Nuc. Sci., vol. 51, Oct. 2004, pp. 2896 -2902 .

[4] W. Abare, F. Brueggman, R. Pease, J. Krieg, and M. Simons, "Comparative analysis of low dose-rate, accelerated, and standard cobalt-60 radiation response data for a low-dropout voltage regulator and a voltage reference," 2000 IEEE Radiation Effects Data Workshop Record, pp. 177-180.

[5] A. H. Johnston, G. M. Swift, and B. G. Rax, "Total dose effects in conventional bipolar transistors and linear integrated circuits," IEEE Trans. Nuc. Sci., vol. 41, Dec. 1994, pp. 2427 - 2436.

[6] R. L. Pease et al., "The Effects of Hydrogen on the Enhanced Low Dose Rate Sensitivity (ELDRS) of Bipolar Linear Circuits," IEEE Trans. Nuc. Sci., vol. 55, Dec. 2008, pp. $3169-3173$.

[7] K. Kruckmeyer, L. McGee, B. Brown, and L. Miller, "Low dose rate test results for National Semiconductor's ELDRS-free LM136-2.5 bipolar reference," IEEE Radiation Effects Data Workshop, Jul. 2009, pp. $47-50$.

[8] R. L. Pease, G. W. Dunham, J. E. Seiler, D. G. Platteter, and S. McClure, "Total dose and dose rate response of an AD590 temperature transducer," IEEE Trans. Nuc. Sci., vol. 54, Aug. 2007, pp. $1049-1054$.

[9] R. L. Pease, S. McClure, J. Gorelick, and S. C. Witczak, "Enhanced low-dose-rate sensitivity of a low-dropout voltage regulator," IEEE Trans. Nuc. Sci., vol. 45, Dec 1998, pp. 2571 - 2578. 